\title{
Heat capacity, entropy, configurational entropy, and viscosity of magnesium silicate glasses and liquids
}

\author{
Juraj Majzlan ${ }^{1}$ D . Jean A. Tangeman ${ }^{2} \cdot$ Edgar Dachs $^{3}$
}

Received: 22 March 2021 / Accepted: 3 July 2021 / Published online: 19 July 2021

(c) The Author(s) 2021

\begin{abstract}
In this work, five $\mathrm{Mg}$-silicate glasses with compositions between $\mathrm{MgSiO}_{3}$ and $\mathrm{Mg}_{2} \mathrm{SiO}_{4}$ were synthesized by aerodynamic levitation combined with laser melting. Low-temperature heat capacity $\left(C_{p}\right)$ was measured (by relaxation calorimetry in the range $2-310 \mathrm{~K}$ ) for all of them, with the resulting vibrational entropies at $T=298.15 \mathrm{~K}$ : sample MG50 with composition $\mathrm{Mg}_{0.996} \mathrm{SiO}_{2.996}$ and entropy $72.88 \mathrm{~J} \mathrm{~mol}^{-1} \mathrm{~K}^{-1}$; MG54 $\mathrm{Mg}_{1.174} \mathrm{SiO}_{3.174} 78.54 ; \mathrm{MG}_{8} \mathrm{Mg}_{1.364} \mathrm{SiO}_{3.364} 85.05 ; \mathrm{MG} \mathrm{Mg}_{1.611}$ $\mathrm{SiO}_{3.611} 91.40$; and $\mathrm{MG} 7 \mathrm{Mg}_{1.907} \mathrm{SiO}_{3.907} 102.75$. Heat capacity of the glasses is higher than that of the corresponding crystal mixtures below $200 \mathrm{~K}$ but plunges below the $\mathrm{C}_{p \text {,crystal }}$ at higher temperatures. High-temperature $C_{p}$ was measured (by differential scanning calorimetry in the range $300-970 \mathrm{~K}$ ) for MG50 and MG67 up to $\approx 1000 \mathrm{~K}$. Using our $C_{p}$ data, selected data for entropies of fusion, $C_{p}$ of crystals, and fictive temperatures, the configurational entropy $\left(S_{\text {conf }}\right)$ at glass transition temperature $\left(T_{\mathrm{g}}\right)$ were calculated. For the near-forsterite glass MG67, the $S_{\text {conf }}$ is $1.9 \mathrm{~J} \mathrm{~mol}{ }^{-1} \mathrm{~K}^{-1}$ at $T_{\mathrm{g}}=1040 \mathrm{~K}$. As this small value is a difference of several large numbers, its uncertainty is relatively high; we consider a conservative estimate of $15 \mathrm{~J}$ $\mathrm{mol}^{-1} \mathrm{~K}^{-1}$. Using the expression $\log \eta=A+B /\left[T S_{\text {conf }}(T)\right]$, the available experimental viscosities $(\eta)$ and the temperaturedependent configurational entropy from our work, we refined the parameters $A=-2.34$ and $B=76,500$ for this equation, with $S_{\text {conf }}(T)=1.90+(83.7 \ln (T / 1040))$. The configurational entropy for the enstatitic MG50 glass is $16.8 \mathrm{~J} \mathrm{~mol}^{-1} \mathrm{~K}^{-1}$ at $T_{\mathrm{g}}$ $=1063 \mathrm{~K}$. The presented data can be combined with enthalpies of formation and thermophysical properties of $\mathrm{Mg}$-silicate glasses for models that could elucidate geological and geophysical observations in the crust and mantle of the Earth.
\end{abstract}

Keywords Silicate glasses $\cdot$ Melts $\cdot$ Heat capacity $\cdot$ Configurational entropy $\cdot$ Viscosity

\section{Introduction}

Silicate glasses are important materials in geology, mineralogy, geochemistry, and geophysics (Mysen and Richet 2005). Their importance relates not particularly to their occurrence in nature but lies mostly in the fact that they open a window for the experimental investigation and understanding of the properties of silicate melts. Melting of the material in the crust and mantle of the Earth is one of the principal

Juraj Majzlan

Juraj.Majzlan@uni-jena.de

1 Institute of Geosciences, Friedrich Schiller University Jena, Burgweg 11, 07749 Jena, Germany

2 Corporate Research Materials Laboratory, 3M Company, Building 201-03-N-06, St. Paul, MN 55144-1000, USA

3 Department of Chemistry and Physics of Materials, University of Salzburg, Jakob-Haringer-Strasse 2a, 5020 Salzburg, Austria processes of this geologically active planet. The two most common rock types of continental and oceanic crust-granite and basalt-both originate from molten silicate liquid generated at depth. A significant amount of data exists on glasses and melts which correspond to the composition of individual minerals (e.g., Robie et al. 1978) or mixed compositions (e.g., Tangeman and Lange 1998). Naturally, the quantity of our knowledge is skewed to the glasses which can be prepared relatively easily and in large quantities in the laboratory and the available data do not cover the geologically important systems in a representative way. In particular, until recently, data were lacking for the intermediate or Mg-dominated compositions of the $\mathrm{MgO}-\mathrm{SiO}_{2}$ system, simply because the preparation of such glasses was difficult or impossible. Tangeman et al. (2001) synthesized a larger amount of $\mathrm{Mg}_{2} \mathrm{SiO}_{4}$ glass using aerodynamic levitation coupled with laser melting (Weber et al. 1994) and opened the possibility to study the Mg-silicate glasses in detail (e.g., Wilding et al. 2004a; Benmore et al. 2011). Such 
glasses were studied by nuclear magnetic resonance (NMR) spectroscopy (e.g., Kroeker and Stebbins 2000), Raman spectroscopy (e.g., Kalampounias et al. 2009), X-ray and neutron scattering (e.g., Wilding et al. 2008), and Brillouin spectroscopy (Speziale et al. 2009). Vibrational properties of these glasses were also studied by molecular dynamics (Belonoshko and Dubrovinsky 1996) and ab initio simulations (Spiekermann et al. 2013).

In this work, we measured the heat capacity $\left(C_{p}\right)$ of the $\mathrm{Mg}$-silicate glasses along the $\mathrm{MgSiO}_{3}-\mathrm{Mg}_{2} \mathrm{SiO}_{4}$ join, corresponding to the compositions of the minerals, enstatiteforsterite, respectively. Most of the data were acquired at low (sub-ambient) temperatures and allow the calculation of entropy at $T=298.15 \mathrm{~K}$. Additional high-temperature data were measured for selected compositions. These data were used, in conjunction with previously published $C_{p}$ for crystalline substances and estimates of $C_{p}$ for supercooled liquids, to calculate configurational entropies of these compositions.

\section{Methods and materials}

The magnesium silicate glasses were synthesized by a technique using aerodynamic levitation combined with laser melting, described previously by Tangeman et al. (2001). Briefly, the precursors for the glass synthesis were prepared by mixing high-purity $\mathrm{MgO}$ and $\mathrm{SiO}_{2}$ powders, laser hearth melting the mixture, and then crushing the centimeter-sized fused granules into millimeter-sized pieces. The pieces were aerodynamically levitated using pure oxygen in a conical nozzle and melted by a continuous-wave $\mathrm{CO}_{2}$ laser. The molten, levitating droplets were then cooled to glass spheroids by blocking the laser beam. The size of the pieces used for the production of glass was dictated by the ability of the material to vitrify; larger pieces could be used for the enstatite compositions that vitrify more easily, the smallest pieces had to be used for the forsterite composition which is the most difficult to vitrify.

Powder X-ray diffraction (XRD) data were measured with a Bruker D8 DaVinci diffractometer with $\mathrm{Cu} \mathrm{K} \alpha$ radiation ( $\lambda=1.54056 \AA$ ). The chemical composition of the samples was determined with a Cameca SX100 electron microprobe under these conditions and with these standards: current 15 $\mathrm{nA}$, accelerating voltage $20 \mathrm{kV}$, beam spot $2 \mu \mathrm{m}$, periclase $(\mathrm{MgO})$ for $\mathrm{Mg}$ and hypersthene (hy-19) $\left((\mathrm{Mg}, \mathrm{Fe}) \mathrm{SiO}_{3}\right)$ for Si.

The heat capacity data were measured by a commercial Physical Properties Measurement System (PPMS) manufactured by Quantum Design ${ }^{\circledR}$. For each experiment, 20.2-25.7 $\mathrm{mg}$ of crushed sample was loaded into an aluminum pan and sealed in air. Cooling in the calorimeter was achieved by liquid nitrogen or helium, as needed. The temperature is measured by two thermocouples; each of them operates in a separate temperature range. The PPMS calorimeter uses the heat-pulse technique, whereby the instrument inputs a known amount of heat into the sample and monitors the temperature change of the sample. Heat capacity was measured in the range of $2-310 \mathrm{~K}$. Calculation of the heat capacity from raw data, the precision, and the accuracy for geological samples has been reviewed by Dachs and Bertoldi (2005). The performance of this instrument was also critically evaluated by Lashley et al. (2003).

The low-temperature $C_{p}$ data measured in this study and those previously published for crystalline enstatite and forsterite were fitted by orthogonal polynomials. A polynomial with odd powers of $T\left(C_{p}=\mathrm{a}_{3} T^{3}+\mathrm{a}_{5} T^{5}+\mathrm{a}_{7} T^{7}\right)$ was used for the extrapolation to $T=0 \mathrm{~K}$. The polynomials were merged at the points where the fitted $C_{p}$ had equal values although usually the slopes of the polynomials were slightly different in these points.

High-temperature $C_{p}$ data were measured with a differential scanning calorimeter (DSC) Setaram DSC-111. The Setaram DSC-111 is a true Calvet microcalorimeter used in scanning mode. Samples were packed into platinum crucibles and measured in the temperature range 300-970 K. Corundum (powdered, $99.997 \%$ metals basis) was used as the heat capacity standard. Quartz and hematite were used to judge the accuracy of the data; the data collected for quartz and hematite deviated less than $2 \%$ from the $C_{p}$ of Robie and Hemingway (1995).

\section{Results}

The chemical composition of the glass spherules does not deviate significantly from the target composition (Table 1). With the exception of MG54, all glasses are slightly depleted in $\mathrm{MgO}$ in comparison to the target composition. This depletion could be caused by a preferential loss of $\mathrm{MgO}$ during the fusion of the starting $\mathrm{MgO}$ and $\mathrm{SiO}_{2}$ powders. No elements other than $\mathrm{Mg}$ and $\mathrm{Si}$ were detected in the electron microprobe analyses. The X-ray diffraction (XRD) patterns of all samples showed only diffuse background with no Bragg peaks. The MG50 and MG67 samples were analyzed by XRD prior to and after the calorimetric measurements and no changes were observed. Previous ${ }^{29} \mathrm{Si}$ nuclear magnetic resonance (NMR) study of the MG67 material Tangeman et al. (2001) showed that approximately $1 \%$ of crystalline forsterite is present in this sample. Such a small amount of crystalline phase could be easily missed by powder XRD.

The thermodynamic functions at $T=298.15 \mathrm{~K}$ for all glasses and crystalline enstatite and forsterite are listed in Table 2. The measured data and the thermodynamic functions in the whole measurement range $(0-300 \mathrm{~K})$ are available as electronic supplementary material. The 
Table 1 Chemical analyses of the studied glasses by electron microprobe

\begin{tabular}{|c|c|c|c|c|c|c|}
\hline Sample & $\mathrm{MgO}$ (wt.\%) & $\mathrm{SiO}_{2}$ (wt.\%) & $\Sigma($ wt. $\%)$ & $\begin{array}{l}100 \mathrm{Mg} /(\mathrm{Mg}+ \\
\mathrm{Si})(\text { molar ratio) }\end{array}$ & Formula & $\begin{array}{l}\text { Formula } \\
\text { weight }(\mathrm{g} \\
\mathrm{mol}^{-1} \text { ) }\end{array}$ \\
\hline MG50 & $40.6(0.3)$ & $60.9(0.9)$ & $101.5(1.0)$ & 49.9 & $\mathrm{Mg}_{0.996} \mathrm{SiO}_{2.996}$ & 100.2278 \\
\hline MG54 & $44.6(0.3)$ & $56.7(0.5)$ & $101.4(0.4)$ & 54.0 & $\mathrm{Mg}_{1.174} \mathrm{SiO}_{3.174}$ & 107.3982 \\
\hline MG58 & $48.6(0.4)$ & $53.1(0.7)$ & $101.7(0.6)$ & 57.7 & $\mathrm{Mg}_{1.364} \mathrm{SiO}_{3.364}$ & 115.0622 \\
\hline MG62 & $52.6(0.3)$ & $48.7(0.8)$ & $101.3(0.8)$ & 61.7 & $\mathrm{Mg}_{1.611} \mathrm{SiO}_{3.611}$ & 125.013 \\
\hline MG67 $^{\mathrm{a}}$ & $56.7(1.0)$ & $44.3(0.6)$ & $101.1(0.5)$ & 65.6 & $\mathrm{Mg}_{1.907} \mathrm{SiO}_{3.907}$ & 136.944 \\
\hline
\end{tabular}

The numbers in parentheses are 2 standard deviations. The target $\mathrm{Mg} /(\mathrm{Mg}+\mathrm{Si})$ value is given as the value in the sample name

${ }^{a}$ Analysis from Tangeman et al. (2001) experimental low-temperature $C_{p}$ data are depicted in Fig. 1 and the data for the MG50 and MG67 glasses are compared to those of their crystalline counterparts. All data are reported on a per mole basis corresponding to a formula $\mathrm{Mg}_{x} \mathrm{SiO}_{2+x}$. When $x=1$, the formula is $\mathrm{MgSiO}_{3}$, that of enstatite, when $x=2$, the formula is $\mathrm{Mg}_{2} \mathrm{SiO}_{4}$, that of forsterite. The values of $x$ and the formula weights used throughout the paper are reported in Table 1.

High-temperature heat capacity was measured for the samples MG50 and MG67 (Fig. 2, data in electronic supporting information). Attempts to approach the glass transition temperature $\left(T_{\mathrm{g}}\right)$ and to measure heat capacities of the supercooled liquids ended with crystallization of the glasses.

High-temperature data sets were fitted with the Berman and Brown (1985) polynomial

$C_{p}=k_{0}+k_{1} T^{-0.5}+k_{2} T^{-2}+k_{3} T^{-3}$

and the polynomial proposed by Richet and Fiquet (1991)

$C_{p}=a+b \ln T+\frac{c}{T}+\frac{d}{T^{2}}+\frac{e}{T^{3}}$

Both of them allow for reliable extrapolation to temperatures somewhat higher than the temperature range of the data used for fitting. The results of these fits are summarized in Table 3.

\section{Discussion}

\section{Comparison of heat capacities of glasses and crystalline mixtures}

The entropies of the glasses at $T=298.15 \mathrm{~K}$, as expected, are larger than those of their crystalline counterparts (Table 2). The entropies of vitrification are relatively small and the driving force for devitrification at room temperature, as expected, is the enthalpy (Fig. 3), not entropy. Both enthalpies and entropies of vitrification vary linearly in the region between $\mathrm{Mg} /(\mathrm{Mg}+\mathrm{Si})$ of 0.5 to $\approx 0.65$. Above this range, toward the composition of forsterite, the linear trends no longer hold (Fig. 4). The deviation from linearity indicates structural changes in the glasses. Indeed, Wilding et al. (2004b) reported discontinuities in the coordination of $\mathrm{Mg}$ in the range of $\mathrm{Mg} /(\mathrm{Mg}+\mathrm{Si})$ of $0.62-0.67$. These structural changes are related to the fractions of $\mathrm{MgO}_{4}$ and $\mathrm{MgO}_{5}$ polyhedra in the glasses.

An interesting observation is that the $C_{p}$ of the glasses plunges below the $C_{p}$ of the corresponding mechanical
Fig. 1 Low-temperature $C_{p}$ data for the glasses from this study: a Data for MG67 and MG50, compared to those of their crystalline counterparts. Data for enstatite from Krupka et al. (1985b), for forsterite from Robie et al. (1982). b Data for the glasses MG54, MG58, and MG62
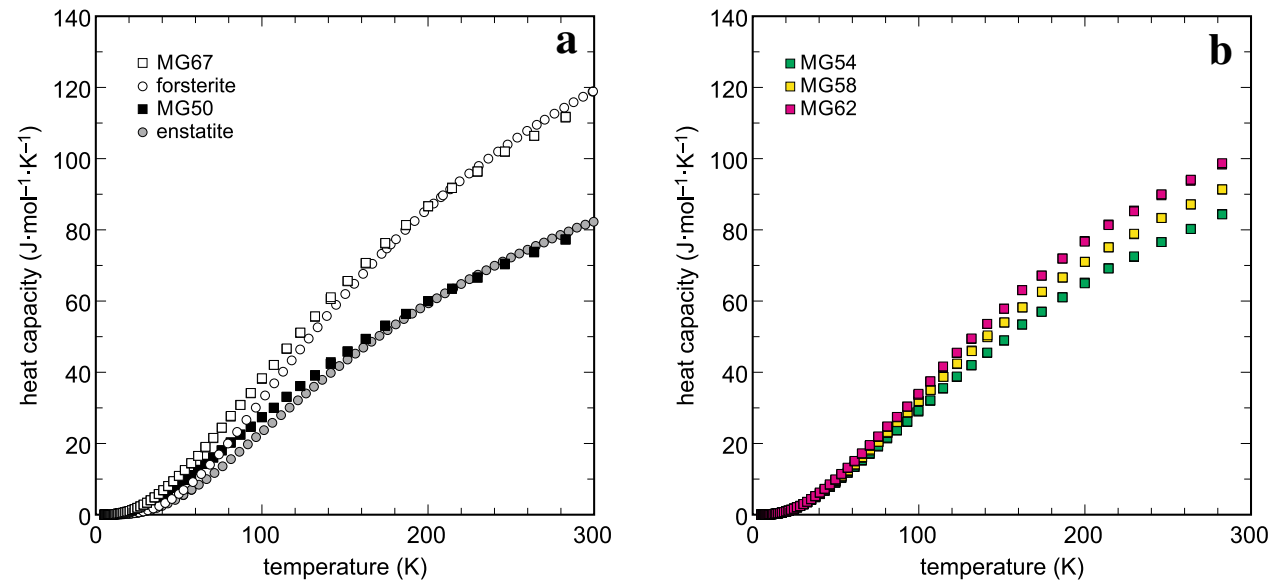
Table 2 Thermodynamic functions of the studied glasses and crystalline forsterite and enstatite at $T=298.15 \mathrm{~K}$

\begin{tabular}{lccl}
\hline Sample & \multicolumn{1}{c}{$\begin{array}{c}C_{p, 298.15}^{o} \mathrm{~J} \\
\mathrm{~mol}^{-1} \mathrm{~K}^{-1}\end{array}$} & $S_{298.15}^{o} \mathrm{~J} \mathrm{~mol}^{-1} \mathrm{~K}^{-1}$ & $H_{298.15}-H_{0} \mathrm{~kJ} \mathrm{~mol}^{-1}$ \\
\hline MG50 & 80.08 & $72.9 \pm 0.9$ & $12.43 \pm 0.15$ \\
MG54 & 87.31 & $78.5 \pm 0.9$ & $13.46 \pm 0.16$ \\
MG58 & 94.36 & $85.1 \pm 1.0$ & $14.62 \pm 0.18$ \\
MG62 & 101.89 & $91.4 \pm 1.1$ & $15.76 \pm 0.19$ \\
MG67 & 115.68 & $102.8 \pm 1.2$ & $17.78 \pm 0.21$ \\
enstatite & 82.05 & $66.3 \pm 0.1$ & $11.99 \pm 0.02$ \\
forsterite & 118.59 & $94.1 \pm 0.1$ & $17.22 \pm 0.03$ \\
\hline
\end{tabular}

$H_{298.15}-H_{0}$ is the heat content (difference in enthalpies) between $T=$ $298.15 \mathrm{~K}$ and $T=0 \mathrm{~K}$. Data for enstatite from Krupka et al. (1985b), for forsterite from Robie et al. (1982). These functions, tabulated at selected temperatures between 0 and $298.15 \mathrm{~K}$ are available as an electronic supporting information to this publication

mixture of the crystals at $\approx 200 \mathrm{~K}$, with the exception of the MG67 glass (Figs. 1a and 5). The $C_{p}$ of the MG67 glass is above that of the corresponding forsterite+enstatite mixture $(\approx 94$ mol.\% forsterite, $\approx 6$ mol.\% enstatite) at all temperatures between 0 and $300 \mathrm{~K}$.

Initially, the observation of lower $C_{p}$ of glass than the $C_{p}$ of the mechanical mixture of forsterite+enstatite was perceived skeptically as an experimental error. This observation, however, was confirmed by the later DSC measurements (Fig. 2) and the negative $\Delta C_{p}\left(=C_{p, \text { glass }}-\Sigma m_{i} C_{p, i}\right.$, where $m_{i}$ is the molar fraction of the crystalline phase $i$ ) values are therefore intrinsic to the samples.

For most of the glasses and their crystalline counterparts, $\Delta C_{p}$ is positive in the region below $400 \mathrm{~K}$ (Robie et al. 1978), i.e., glasses have a higher $C_{p}$ than the crystals.
An exception is our MG50-MG62 glasses and the anorthite glass (Robie et al. 1978) (Fig. 5). All glasses, however, show a peak in the $\Delta C_{p}$ function, where the difference is at its maximum. For our $\mathrm{Mg}$-silicate glasses, the peak occurs at $\approx$ $80 \mathrm{~K}$, while for the glasses with compositions near $\mathrm{NaAlSi}_{3}$ $\mathrm{O}_{8}, \mathrm{KAlSi}_{3} \mathrm{O}_{8}, \mathrm{CaAl}_{2} \mathrm{Si}_{2} \mathrm{O}_{8}$ (the compositions of feldspar end-members), the peak was found at 30-50 K (Robie et al. 1978).

\section{Boson peak in the heat capacity of the glasses}

Heat capacity of glasses has been shown to deviate significantly from the Debye law $C_{p}=A_{3} T^{3}$ at low temperatures (< 50 K) (e.g., Pohl 1981; Zotov 2002; Richet 2009). This anomaly can be approximately described by Bose-Einstein statistics and is therefore called the boson peak.

Heat capacity of alkaline earth silicate glasses was investigated in a detail by Richet et al. (2009). They showed that the intensity of the boson peak scales with the mass of the alkaline earth cations, being the highest for $\mathrm{Ba}^{2+}$ and the smallest for $\mathrm{Mg}^{2+}$ (Fig. 6a). Their Mg silicate glass had composition $\mathrm{Mg}_{1.12} \mathrm{Si}_{0.88} \mathrm{O}_{2.88}$. In the terminology used in this paper, such composition corresponds to MG56.

The data for MG56 of Richet et al. (2009) overlap closely with the data for our sample MG58 (Fig.6b). The data for MG54 and MG50 lie above and the data for MG62 and MG67 below. Overall, these observations agree with the conclusion of Buchenau et al. (1986) that the intensity of the boson peak should decrease with decreasing degree of tetrahedral polymerization in the silicate glasses. At the top of the boson peak, however, the data for MG67 are slightly higher than those for MG62, suggesting that the polymerization degree is not the only
Fig. 2 Low-temperature (large circles) and high-temperature (small circles, only selected data points shown) $C_{p}$ data for the glasses MG50 and MG67. The solid thin lines show the Richet-Fiquet fits to the hightemperature $C_{p}$ data

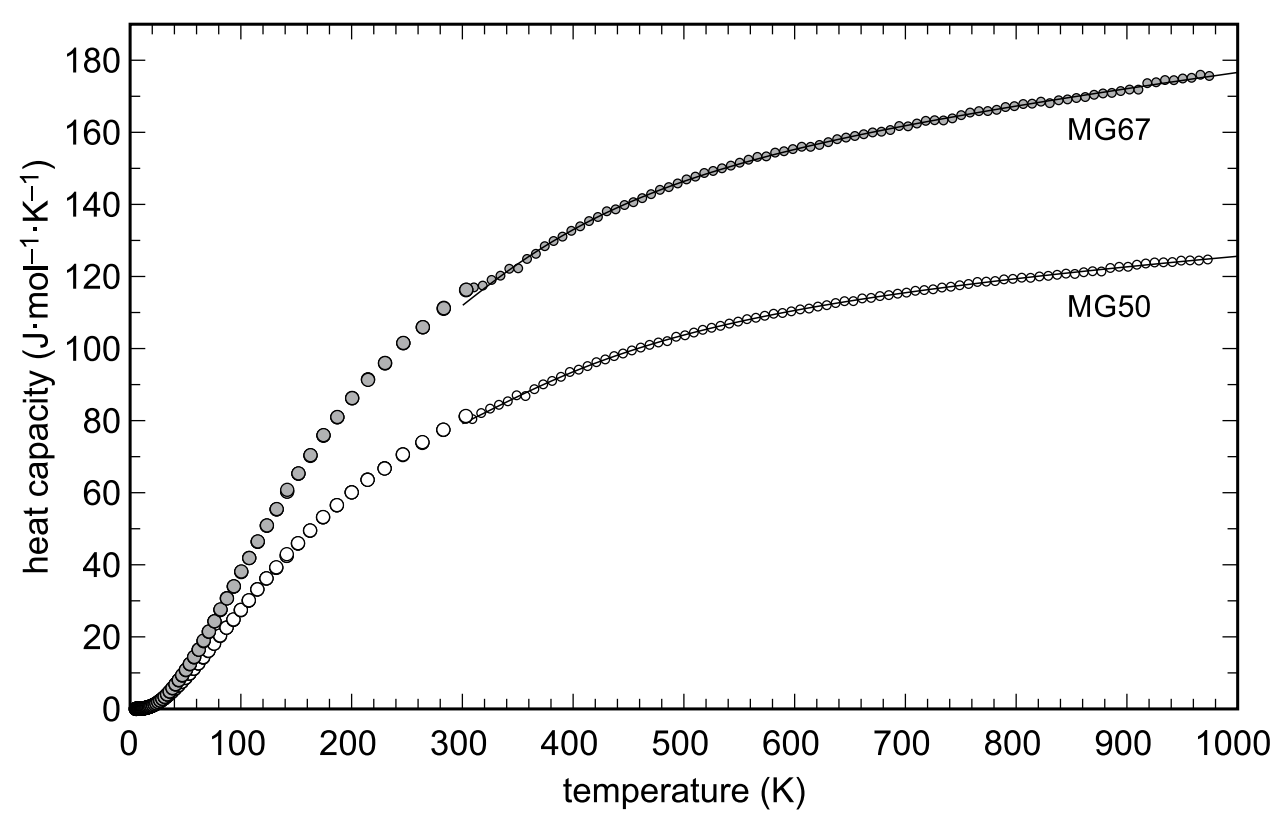


Table 3 Heat capacity polynomial coefficients for the polynomials proposed by Berman and Brown (1985, eq. 1) and Richet and Fiquet (1991, eq. 2)

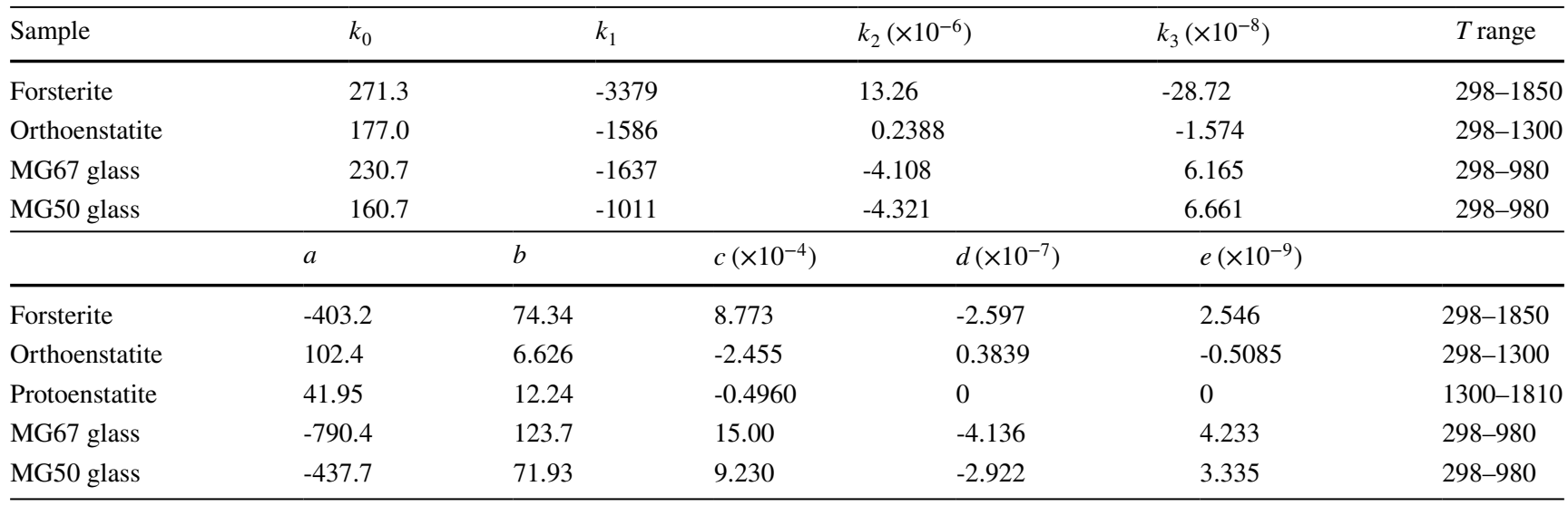

Data for the crystalline substances from Gillet et al. (1991), Krupka et al. (1985a), Thiéblot et al. (1999). For details, see text

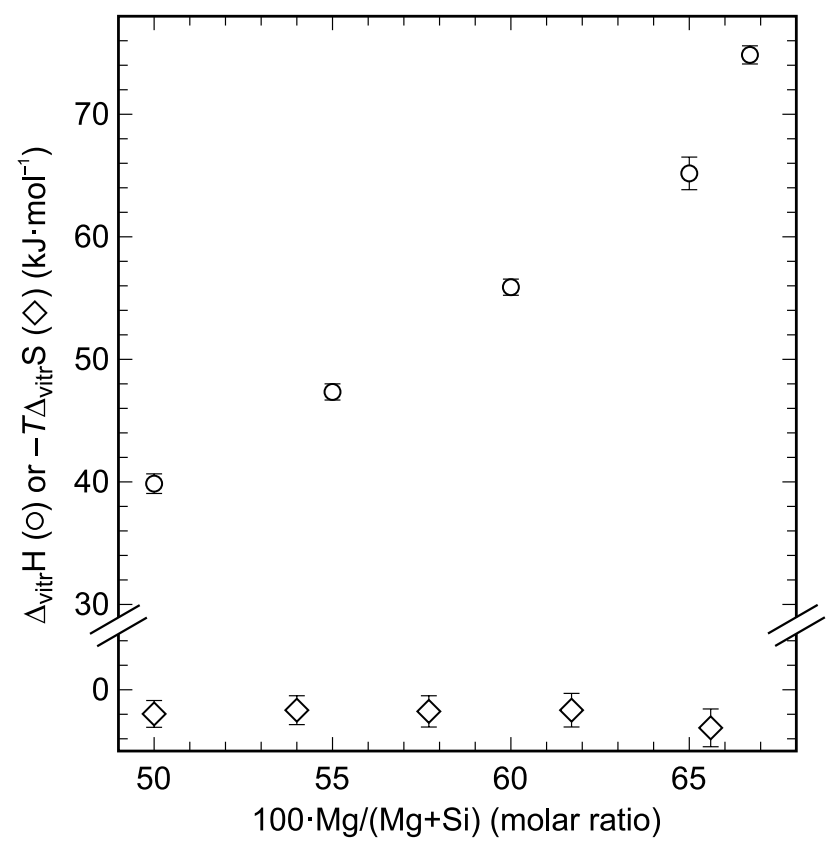

Fig. 3 Enthalpies of vitrification $\left(\Delta_{\text {vitr }} H\right.$, Nasikas and Navrotsky 2014) and $-T \Delta_{\text {vitr }} S$ values from this work, both at $T=298.15 \mathrm{~K}$. Note that the values from Nasikas and Navrotsky (2014) were recalculated to the formulae $\mathrm{Mg}_{x} \mathrm{SiO}_{2+x}$ used in this work (they normalized the compositions to $2 \mathrm{O}$ atoms, not $1 \mathrm{Si}$ atom as in this work)

variable that controls the intensity and shape of the boson peak. Coordination changes of $\mathrm{Mg}$ (Wilding et al. 2004b) may play also a role although the quantification of such effects is very difficult.

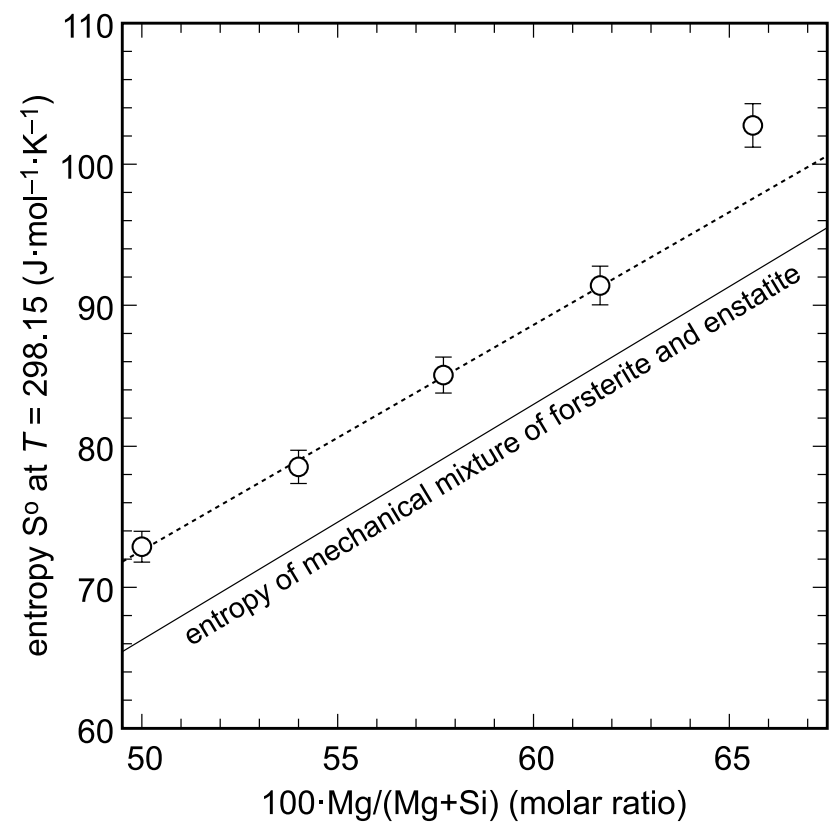

Fig. 4 Entropies of the magnesium silicate glasses and the corresponding mechanical mixtures of enstatite and forsterite, all at $T=$ $298.15 \mathrm{~K}$. The dashed line is a fit through the data for MG50, MG54, MG58, and MG62, and shows the deviation of the sample MG67 from this linear trend

\section{Configurational entropy of forsteritic glass}

The configurational entropy of a glass at the fictive temperature $\bar{T}$ (defined below) can be calculated from an equation (Richet 1984) (corrected because entropy is obtained by integrating $C_{p} / T \mathrm{~d} T$ (or $C_{p} \mathrm{~d} \ln T$ ) and not $C_{p} \mathrm{~d} T$ ) 


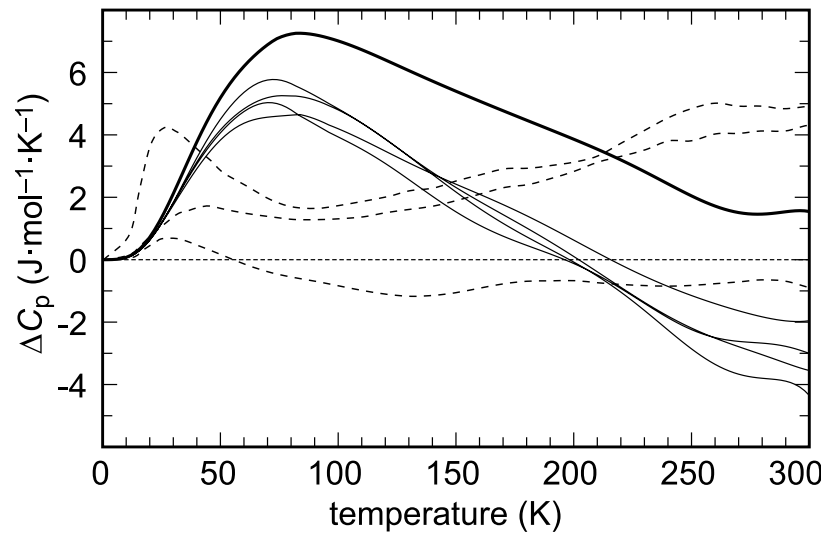

Fig. 5 Differences in the heat capacity $\left(\Delta C_{p}\right)$ between glasses and corresponding crystalline phases or mixtures thereof: MG67-thick solid line, other glasses from this work-thin solid lines, glasses with compositions near $\mathrm{NaAlSi}_{3} \mathrm{O}_{8}, \mathrm{KAlSi}_{3} \mathrm{O}_{8}, \mathrm{CaAl}_{2} \mathrm{Si}_{2} \mathrm{O}_{8}$ (the compositions of feldspar end-members)-dashed lines (redrawn from Robie et al. 1978).

$$
\begin{aligned}
S_{\text {conf }}(\bar{T})= & S_{\text {cc }}+\int_{0}^{T_{\text {fusion }}} C_{p, \text { crystal }} \mathrm{d} \ln T \\
& +\Delta_{\text {fusion }} S+\int_{T_{\text {fusion }}}^{\bar{T}} C_{p, \text { liquid }} \mathrm{d} \ln T \\
& +\int_{\bar{T}}^{0} C_{p, \text { glass }} \mathrm{d} \ln T
\end{aligned}
$$

where $S_{\text {cc }}$ is the zero-point entropy of the crystal, $\Delta_{\text {fusion }} \mathrm{S}$ is the entropy of fusion which occurs at temperature $T_{\text {fusion }}$, and $\bar{T}$ is the fictive temperature. The fictive temperature, $\bar{T}$, of a glass is the "temperature at which the actual configurational state of a glass would be the equilibrium configuration of the liquid; operationally, is the glass transition temperature on cooling" (Richet 1984).

For the compositions considered in this study, the $S_{\mathrm{cc}}$ values are 0 because neither enstatite nor forsterite structures are disordered. Parts of the integrals were already evaluated by calculation of the entropy at $T=298.15 \mathrm{~K}$ (as $S_{298.15}^{o}=S^{o}$ in Table 2). The expression can be re-written as

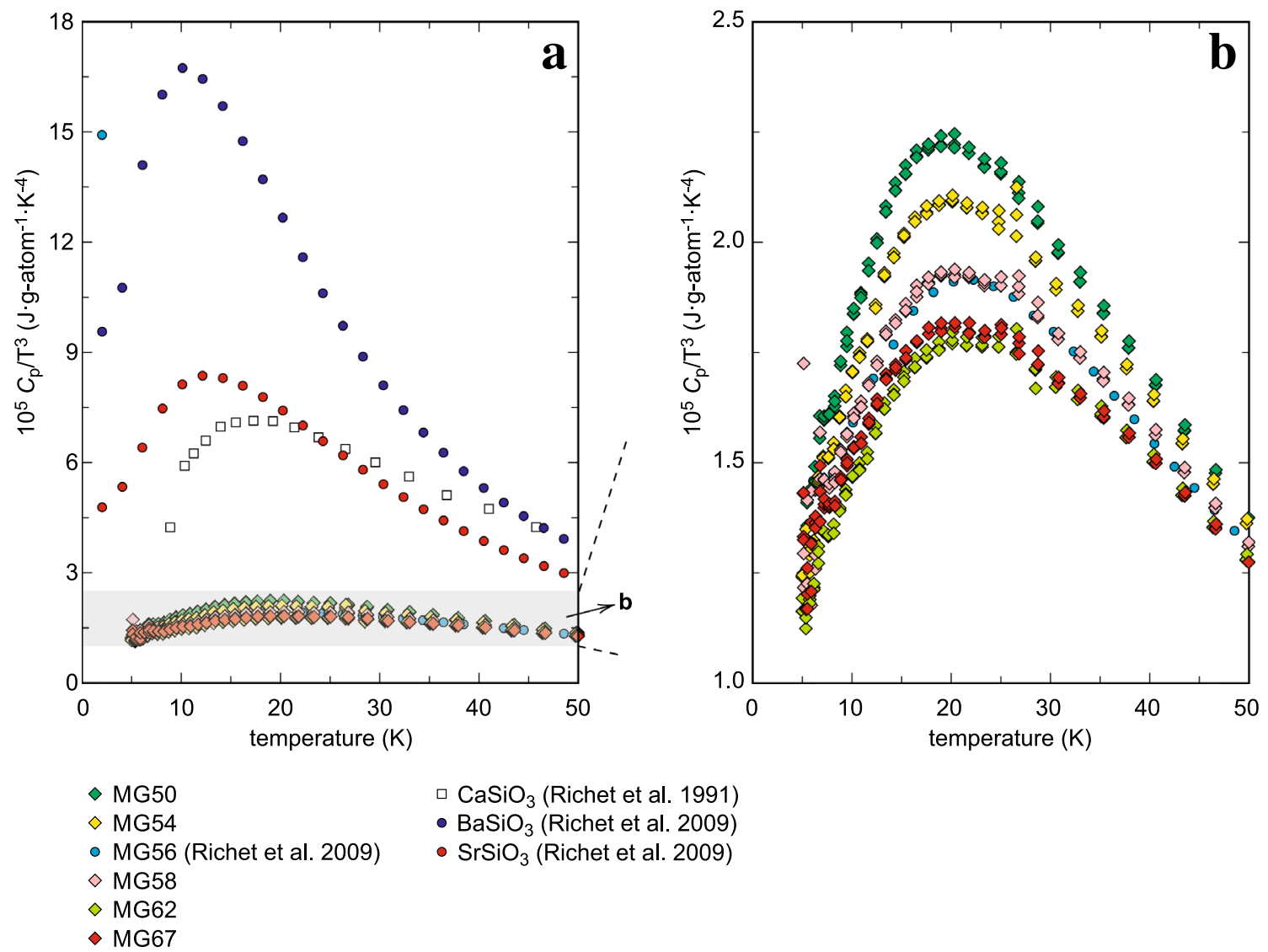

Fig. 6 Boson peaks of silicate glasses with alkaline earth cations. a Overview documenting the increase of the intensity of the boson peaks with the mass of the alkaline earth cation; $\mathbf{b}$ detail (gray shaded area in a) showing the boson peaks for the magnesium silicate glasses 


$$
\begin{aligned}
S_{\text {conf }}(\bar{T})= & S_{\text {crystal }}^{o}+\int_{T^{o}}^{T_{\text {fusion }}} C_{p, \text { crystal }} \mathrm{d} \ln T \\
& +\Delta_{\text {fusion }} S \\
& +\int_{T_{\text {fusion }}}^{\bar{T}} C_{p, \text { liquid }} \mathrm{d} \ln T-S_{\text {glass }}^{o} \\
& +\int_{\bar{T}}^{T^{o}} C_{p, \text { glass }} \mathrm{d} \ln T
\end{aligned}
$$

It would be interesting and desirable to calculate the configurational entropies of the studied glasses. When reviewing the available literature and data, however, we found that some important data are missing or are rather scattered. For example, the fusion enthalpy of forsterite was measured by Navrotsky et al. (1989) and Richet et al. (1993). The two fusion enthalpies differ but overlap within their uncertainties: (Navrotsky et al. 1989) $114.0 \pm 20.0 \mathrm{~kJ} \mathrm{~mol}^{-1}$ (at 2163 $\mathrm{K}$ ), (Richet et al. 1993) $142.0 \pm 14.0 \mathrm{~kJ} \mathrm{~mol}^{-1}$ (at 2174 K). Kojitani and Akaogi (1997) used these two values to evaluate the non-ideal nature of mixing in the melts of the $\mathrm{CaO}-\mathrm{MgO}-\mathrm{Al}_{2} \mathrm{O}_{3}-\mathrm{SiO}_{2}$ system. They concluded that if the value of Richet et al. (1993) is used, the mixing within this system is ideal. On the other hand, the value of Navrotsky et al. (1989) suggests a positive mixing enthalpy. Additional scattered estimates of $\Delta_{\text {fusion }} H$ for forsterite were provided in the earlier literature (Bottinga and Richet 1978; Ghiorso and Carmichael 1980; Stebbins et al. 1984) but were made obsolete but the above-mentioned measurements of Navrotsky et al. (1989) and Richet et al. (1993).

Using the simple expression $\Delta_{\text {fusion }} S=\Delta_{\text {fusion }} H / T_{\text {fusion }}$, we get an entropy of fusion of $52.7 \pm 9.2 \mathrm{~J} \mathrm{~mol}^{-1} \mathrm{~K}^{-1}$ from Navrotsky et al. (1989) and of $65.3 \pm 6.4 \mathrm{~J} \mathrm{~mol}^{-1} \mathrm{~K}^{-1}$ from Richet et al. (1993).

The fictive temperature $\bar{T}$ of the MG67 glass is unknown because this glass crystallizes before it enters the glass-transition region. However, Tangeman et al. (2001) assumed that crystallization is initiated just before the glass transition and estimated $T_{\mathrm{g}}$ as $1040 \mathrm{~K}$. Richet et al. (1993) estimated $T_{\mathrm{g}}$ of the forsteritic glass at a temperature of $990 \pm 10 \mathrm{~K}$ when the configuration entropy of such glass would vanish. Our data (Fig. 2) show no sign of glass transition or crystallization up to $970 \mathrm{~K}$ and Tangeman et al. (2001) showed that the glass transition region is not entered at temperatures even slightly higher than $1000 \mathrm{~K}$. Therefore, we assume that the fictive temperature is equal to $1040 \mathrm{~K}$, in line with the earlier estimate of Tangeman et al. (2001).

A greater difficulty is encountered when seeking the $C_{p}$ of the supercooled liquids. The temperatures at which they exist exceed the normal temperature range of operation of many calorimeters. The Mg-silicate glasses tend to crystallize upon or soon after the glass transition, thus precluding the $C_{p}$ measurement at very high temperatures. Tangeman et al. (2001) estimated the average $C_{p}$ of $\mathrm{Mg}_{2} \mathrm{SiO}_{4}$ supercooled liquid as $225 \mathrm{~J} \mathrm{~mol}^{-1} \mathrm{~K}^{-1}$ for the temperature range 1040-1773 K, based on solution calorimetry work of Navrotsky et al. (1989). Stebbins et al. (1984) and Lange and Navrotsky (1992) calculated the $C_{p}$ of supercooled $\mathrm{Mg}_{2}$ $\mathrm{SiO}_{4}$ liquid as $285-295 \mathrm{~J} \mathrm{~mol}^{-1} \mathrm{~K}^{-1}$ from partial molar heat capacities in the range $1200-1850 \mathrm{~K}$. Using first principles molecular dynamics simulations, de Koker et al. (2008) derived $C_{v}$ for $\mathrm{Mg}_{2} \mathrm{SiO}_{4}$ liquid at $T=2163 \mathrm{~K}$ as $265 \mathrm{~J}$ $\mathrm{mol}^{-1} \mathrm{~K}^{-1}$. Navrotsky et al. (1990) listed the average difference between the $C_{p}$ of forsterite crystal and $C_{p}$ of $\mathrm{Mg}_{2}$ $\mathrm{SiO}_{4}$ liquid, $\Delta C_{p}$, as $35 \mathrm{~J} \mathrm{~mol}^{-1} \mathrm{~K}^{-1}$. This value would lead to $C_{p \text {,liquid }}(T=1100 \mathrm{~K})$ of $214 \mathrm{~J} \mathrm{~mol}^{-1} \mathrm{~K}^{-1}$, taking the $C_{p}$ data for forsterite crystal from Gillet et al. (1991). Navrotsky et al. (1990) also used earlier data of Ghiorso and Carmichael (1980) and Ghiorso and Carmichael (1987) to arrive at a $\Delta C_{p}$ value of $64 \mathrm{~J} \mathrm{~mol}^{-1} \mathrm{~K}^{-1}$, leading to $C_{p \text {,liquid }}$ $(T=1100 \mathrm{~K})$ of $243 \mathrm{~J} \mathrm{~mol}^{-1} \mathrm{~K}^{-1}$.

Using the data derived in this work and discussed above, we attempted to calculate the configurational entropy of the MG67 glass, close to the forsterite composition. The $S_{\mathrm{cc}}$ value was taken as $0 \mathrm{~J} \mathrm{~mol}^{-1} \mathrm{~K}^{-1}$; the entropy of fusion as a mean of the two values above, $59 \mathrm{~J}$ $\mathrm{mol}^{-1} \mathrm{~K}^{-1}$. The entropies of crystal and glass at $T=298.15$ are listed in Table 2. The coefficients for $C_{p}$ polynomials used are listed in Table 3. Both types of polynomials (Berman-Brown and Richet-Fiquet) performed in a similar way, the differences in the integrals being negligible $(<0.05 \%)$. The least certain value is the $C_{p}$ of the liquid. We adopted a mean of the estimates above (Stebbins et al. 1984; Lange and Navrotsky 1992; Tangeman et al. 2001; de Koker et al. 2008), $260 \mathrm{~J} \mathrm{~mol}^{-1} \mathrm{~K}^{-1}$. Using these data, the configurational entropy of MG67 glass at $T_{\mathrm{g}}$ was estimated as $1.9 \mathrm{~J} \mathrm{~mol}^{-1} \mathrm{~K}^{-1}$ (for the composition $\mathrm{Mg}_{1.907}$ $\mathrm{SiO}_{3.907}$ ) or $0.7 \mathrm{~J} \mathrm{gfw}^{-1} \mathrm{~K}^{-1}$ (for the composition normalized to 1 cation, $\left.\mathrm{Mg}_{0.656} \mathrm{Si}_{0.344} \mathrm{O}_{1.344}\right)$. This small configurational entropy agrees with the prediction of Richet et al. (1993) that it would be essentially zero at $T_{\mathrm{g}}$. This conclusion was derived by extrapolation of viscosity data for $\mathrm{Mg}$ aluminosilicate melts. The validity of $\mathrm{S}_{\text {conf }}$ derived in our study could be strengthened, however, if a more precise determination of $C_{p \text {,liquid }}$ was available.

The $S_{\text {conf }}$ calculated according to equation (6) is a composite value whose uncertainty is difficult to judge. The uncertainties on $S_{\text {glass }}^{o}$ and $S_{\text {crystal }}^{o}$ are relatively small, on the order of $1 \mathrm{~J} \mathrm{~mol}^{-1} \mathrm{~K}^{-1}$ or less (see Table 2). The uncertainty of $\Delta_{\text {fusion }} S$ is much higher, almost $10 \mathrm{~J} \mathrm{~mol}^{-1} \mathrm{~K}^{-1}$. The superambient heat capacities of crystals and glasses, both experimentally measured, are also well constrained. In the absence of $C_{p}$ anomalies, one can count with overall precision of $3 \%$. Finally, the $C_{p}$ of the liquid, derived by a mathematical regression on several liquid compositions 
(Courtial and Richet 1993) introduces another potential error. Hence, it seems that a conservative estimate of the overall uncertainty on the $S_{\text {conf }}$ could be $15 \mathrm{~J} \mathrm{~mol}^{-1} \mathrm{~K}^{-1}$, much more than the value of this variable itself. Such state of affairs is, however, typical for small numbers determined as a difference of several large numbers. Despite of the large ratio of the error and the value of $S_{\text {conf }}$, we still consider this value to be a fairly accurate estimate and proceed to calculate further associated quantities from it.

The configurational entropy at a higher temperature $T$ can be calculated as

$S_{\text {conf }}(T)=S_{\text {conf }}\left(T_{\mathrm{g}}\right)+\int \frac{C_{p, \text { conf }}}{T} \mathrm{~d} T$

where

$C_{p, \text { conf }}(T)=C_{p, \text { liquid }}(T)-C_{p, \text { glass }}\left(T_{\mathrm{g}}\right)$

The results of such a calculation for MG67 glass are shown in Fig. 7. In this case, $C_{p \text {,conf }}$ is a constant, because $C_{p \text {,liquid }}$ is considered to be a constant.

\section{Viscosity of forsteritic liquids}

The consequence of the rapid increase of the configurational entropy is flattening of the viscosity-temperature curve at high temperatures, a typical feature of 'fragile', non-Arrhenian liquids (cf. Lange and Navrotsky 1993). Hence, initial rapid drop in viscosity just above $T_{\mathrm{g}}$ will be

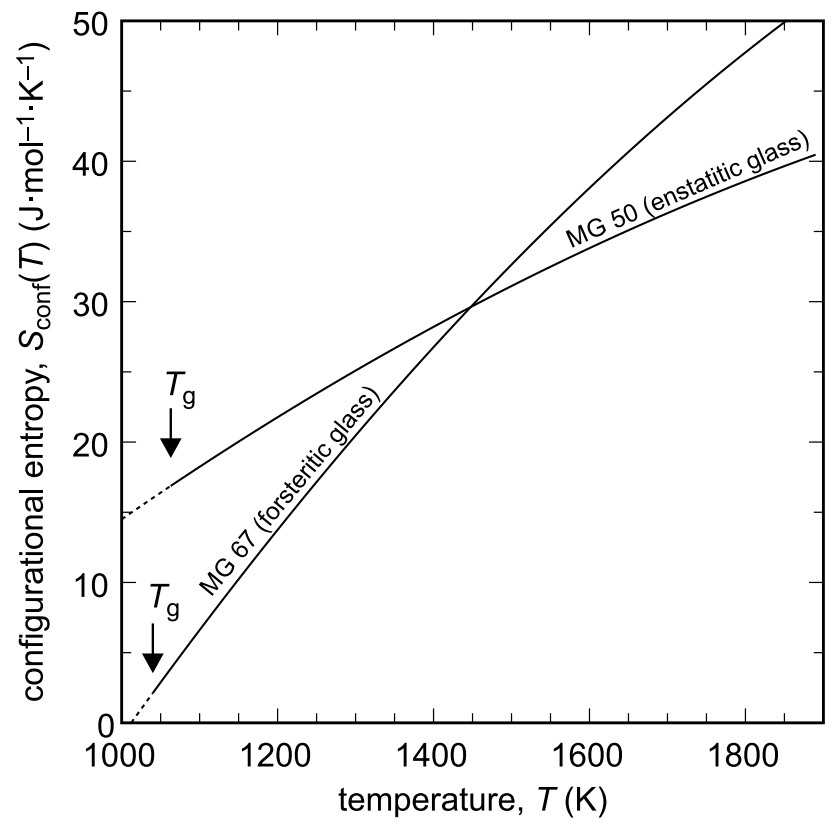

Fig. 7 Calculated configurational entropy for the samples MG50 and MG67, representing enstatitic and forsteritic supercooled liquids, respectively. $T_{\mathrm{g}}$ is glass-transition temperature replaced by a nearly constant viscosity of such melts at high temperatures. The relationship between configurational entropy and viscosity, $\eta$, is Adam and Gibbs (1965):

$\log \eta=A+\frac{B}{T S_{\text {conf }}(T)}$

Because of experimental difficulties, the viscosities were measured at elevated temperatures and pressures preferentially for fayalitic, not for forsteritic liquids (e.g., Shiraishi et al. 1978; Spice et al. 2015). Viscosities of peridotitic, forsterite-similar liquid were measured over a broad $P-T$ range by Liebske et al. (2005) and calculated at high temperatures by Lacks et al. (2007) and Adjaoud et al. (2008). All these data are shown in Fig. 8 and were used to fit the parameters $A$ and $B$ in eq. 7. The resulting parameters are $A=-2.34$ and $B=76,500$, with $S_{\text {conf }}(T)=1.90+(83.7 \ln (T / 1040))$. The predicted variation of viscosity with temperature is shown in Fig. 8. The data of Urbain et al. (1982) are also shown in Fig. 8 but were not used for fitting because they appear somewhat lower than the other available values.

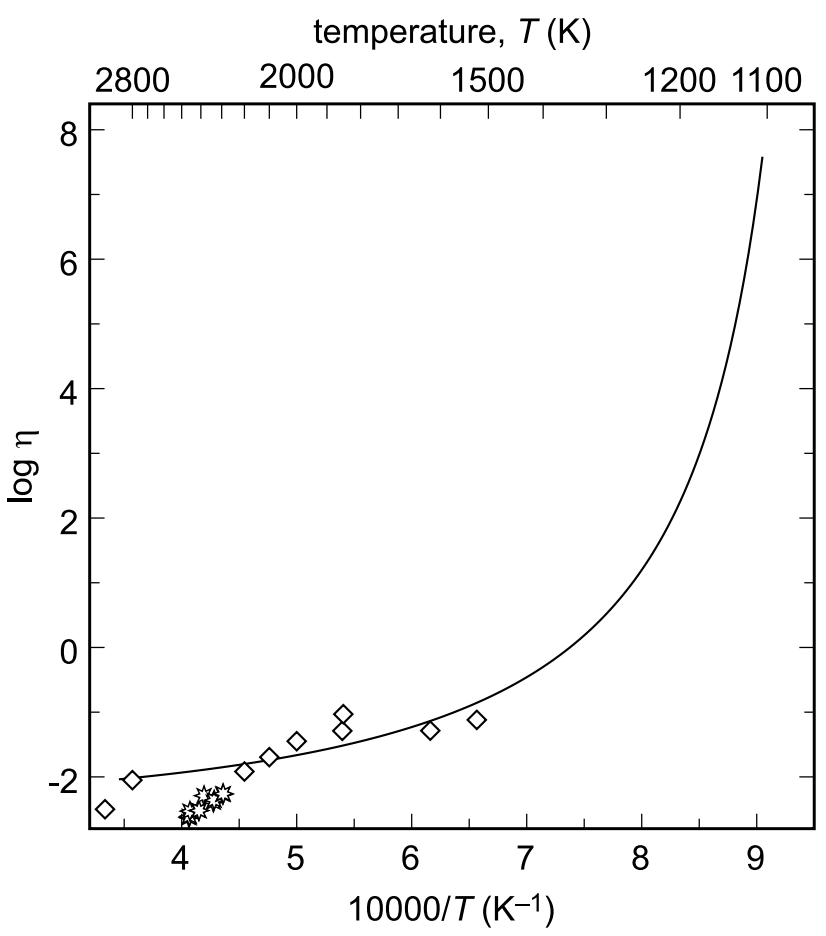

Fig. 8 Calculated viscosity of a forsteritic liquid (this work, parameters of the equation in text) and experimental data: diamonds-data used for fitting (Shiraishi et al. 1978; Spice et al. 2015; Liebske et al. 2005; Lacks et al. 2007; Adjaoud et al. 2008); stars-data from Urbain et al. (1982) 


\section{Partial molar heat capacities in magnesium silicate liquids}

The least certain parameter in the calculation above appears to be $C_{p \text {,liquid }}$. The easiest method to tabulate heat capacities of silicate liquids is the determination of partial molar heat capacities $\left(\bar{C}_{p, i}\right)$ of the oxide components. Stebbins et al. (1984) and Courtial and Richet (1993) derived a set of $\bar{C}_{p, i}$ values. It could be expected that one of the most accurate values is that for $\mathrm{SiO}_{2}$. Many silicate compositions were measured and direct measurements on $\mathrm{SiO}_{2}$ glasses and liquids are also possible. The $\bar{C}_{p, \mathrm{SiO}_{2}}$ value in Courtial and Richet (1993) is $81.37 \mathrm{~J} \mathrm{gfw}^{-1} \mathrm{~K}^{-1}$, that in Stebbins et al. (1984) $80.0 \pm 0.9 \mathrm{~J} \mathrm{gfw}^{-1} \mathrm{~K}^{-1}$. The $\bar{C}_{p, \mathrm{MgO}}$ of $85.78 \mathrm{~J} \mathrm{gfw}^{-1}$ $\mathrm{K}^{-1}$ in Courtial and Richet (1993) superseeded the older and higher estimate in Stebbins et al. (1984) (99.7 $\mathrm{J} \mathrm{gfw}^{-1} \mathrm{~K}^{-1}$ ) that was less certain and based only on a few experimental points.

Using the $\bar{C}_{p, i}$ from Courtial and Richet (1993), the $C_{p \text {,liquid }}\left(\mathrm{Mg}_{2} \mathrm{SiO}_{4}\right)$ is $253 \mathrm{~J} \mathrm{~mol}^{-1} \mathrm{~K}^{-1}$ but the earlier data from Stebbins et al. (1984) give $279.4 \mathrm{~J} \mathrm{~mol}^{-1} \mathrm{~K}^{-1}$. The latter datum, however, would lead to negative configurational entropies for forsteritic glasses at $T_{\mathrm{g}}$. If $\bar{C}_{p, \mathrm{MgO}}$ is set to 90 $\mathrm{J} \mathrm{gfw}^{-1} \mathrm{~K}^{-1}$, then $C_{p \text {,liquid }}\left(\mathrm{Mg}_{2} \mathrm{SiO}_{4}\right)$ is $260 \mathrm{~J} \mathrm{~mol}^{-1} \mathrm{~K}^{-1}$, the value obtained above as a mean of available estimates and applied in the calculations. The adjusted $\bar{C}_{p, \mathrm{MgO}}$ value is between the values proposed by Stebbins et al. (1984) and Courtial and Richet (1993). The parameters proposed by Courtial and Richet (1993) appear to be more accurate but it is not clear to what extent do they apply to $\mathrm{Mg}_{2} \mathrm{SiO}_{4}$ composition. As shown above (e.g., Figs. 3, 4), the properties of the $\mathrm{Mg}_{2} \mathrm{SiO}_{4}$ glass deviate from linear trends defined by $\mathrm{Mg}$-silicate glasses with higher $\mathrm{SiO}_{2}$ proportions. For consistency, we will use the $\bar{C}_{p, \mathrm{MgO}}$ of $90 \mathrm{~J} \mathrm{gfw}^{-1} \mathrm{~K}^{-1}$ also for enstatitic melts below, with $C_{p, \text { liquid }}\left(\mathrm{MgSiO}_{3}\right)=170 \mathrm{~J}$ $\mathrm{mol}^{-1} \mathrm{~K}^{-1}$. The $C_{p, \text { liquid }}\left(\mathrm{MgSiO}_{3}\right)$ derived from Courtial and Richet (1993) is $167 \mathrm{~J} \mathrm{~mol}^{-1} \mathrm{~K}^{-1}$, only marginally different from this value.

\section{Configurational entropy of enstatitic glass}

For enstatite, the enthalpy of fusion is $75.3 \pm 6.0 \mathrm{~kJ} \mathrm{~mol}^{-1}$ (cf. Stebbins et al. 1984; Richet and Bottinga 1986) at $T_{\text {fusion }}=$ 1834 K, although Stebbins et al. (1984) discussed additional scattered values for $\Delta_{\text {fusion }} H$. The resulting entropy of fusion is $41.1 \mathrm{~J} \mathrm{~mol}^{-1} \mathrm{~K}^{-1}$. The glass transition temperature was determined by Briggs (1975) as $1063 \mathrm{~K}$. The fits to the $C_{p}$ data for the MG50 glass are presented in Table 3.

A challenge in the case of enstatite is the integration of its heat capacity up to the melting temperature of $1834 \mathrm{~K}$. Upon heating, orthoenstatite transforms to clino- and protoenstatite and shows significant pre-melting phenomena (Thiéblot et al. 1999). Measurements on orthoenstatite extend well into the stability field of clinoenstatite but generally agree well with each other (White 1919; Krupka et al. 1985a; Thiéblot et al. 1999). At $T=1300 \mathrm{~K}$, orthoenstatite transforms to protoenstatite, with an associated $C_{p}$ drop. The available $C_{p}$ data were therefore re-fitted (orthoenstatite) or adopted (protoenstatite) and the resulting polynomials are summarized in Table 3.

Another question is the entropy of the ortho- to protoenstatite transition. Thiéblot et al. (1999) measured the enthalpy of transformation as $2 \mathrm{~kJ} \mathrm{~mol}^{-1}$ but they were not certain if the results can be interpreted in terms of a complete transformation. Gasparik (1990) estimated 9-11 kJ $\mathrm{mol}^{-1}$ for this transformation. These differences account for transformation entropies of $1.5-8.5 \mathrm{~J} \mathrm{~mol}^{-1} \mathrm{~K}^{-1}$ and introduce an additional large uncertainty in the calculation of the configurational entropy. The $\Delta H$ values of 9-11 kJ $\mathrm{mol}^{-1}$ seem to be too large for a displacive transformation, however. For comparison, the enthalpy of $\alpha-\beta$ quartz transformation is $0.5 \mathrm{~kJ} \mathrm{~mol}^{-1}$ (average of values found in the literature, see Sheffield 1994). Even for reconstructive transformations of polymorphs of simple composition and structure, the enthalpies are small, e.g., for andalusite-sillimanite transformation, $\Delta H$ is $2 \mathrm{~kJ} \mathrm{~mol}^{-1}$ or less (Salje and Werneke 1982). Therefore, we adopt the $\Delta H$ value from Thiéblot et al. (1999) with the corresponding $\Delta S$ of $1.5 \mathrm{~J} \mathrm{~mol}^{-1} \mathrm{~K}^{-1}$.

The configurational entropy at $T_{\mathrm{g}}$ for enstatitic glass is calculated as $16.8 \mathrm{~J} \mathrm{~mol}^{-1} \mathrm{~K}^{-1}$, including the contribution of $\Delta_{\text {ortho } \rightarrow \text { proto }} S$ of $1.5 \mathrm{~J} \mathrm{~mol}^{-1} \mathrm{~K}^{-1}$ (Fig. 7). The comparison of the magnitude of the $\Delta_{\text {ortho } \rightarrow \text { proto }} S$ values $\left[1.5 \mathrm{~J} \mathrm{~mol}^{-1} \mathrm{~K}^{-1}\right.$ from Thiéblot et al. (1999) versus $8.5 \mathrm{~J} \mathrm{~mol}^{-1} \mathrm{~K}^{-1}$ from Gasparik (1990)] makes it clear that the ortho- to protoenstatite transformation is potentially a source of large error. Stebbins et al. (1984) report $\mathrm{S}_{\text {conf }}\left(T / T_{\mathrm{g}}=1.5\right)=3.4 \mathrm{~J} \mathrm{~g}$-atom ${ }^{-1} \mathrm{~K}^{-1}$, equal to $17 \mathrm{~J} \mathrm{~mol}^{-1} \mathrm{~K}^{-1}$. Our results are higher than this datum; calculation at higher temperatures with our data and assumptions give $\mathrm{S}_{\text {conf }}\left(T / T_{\mathrm{g}}=1.5\right)=32 \mathrm{~J} \mathrm{~mol}^{-1} \mathrm{~K}^{-1}$. Obviously, the difficulties related to the thermodynamics of the $\mathrm{MgSiO}_{3}$ polymorphs must be resolved before the thermodynamic assessment of the configurational entropy of enstatitic glass can continue.

\section{Conclusions}

Using new thermodynamic data for magnesium silicate glasses, we derived configurational entropies of forsteritic and enstatitic supercooled liquids and point at discrepancies that may introduce substantial errors in these calculations. These data allow the prediction of viscosities of such liquids at temperatures which are not accessible experimentally. Such data can be used in modeling and supporting of algorithms to define thermodynamic properties of a range of vitreous substances and melts (e.g., Jacobs et al. 2017). 
They can be combined with enthalpies of formation (Nasikas and Navrotsky 2014) and thermophysical properties (Jacobs and de Jong 2007) for models that could elucidate geological and geophysical observations in the crust and mantle of the Earth.

Supplementary Information The online version contains supplementary material available at https://doi.org/10.1007/s00269-021-01153-7.

Acknowledgements We are very thankful to Pascal Richet and an anonymous reviewer for their constructive criticism that helped to improve this manuscript. We thank Rebecca Stevens for help and guidance with the $C_{p}$ data fitting and Hiltrud Müller-Sigmund for the help with the microprobe measurements.

Funding Open Access funding enabled and organized by Projekt DEAL.

Data availability The measured low-temperature (PPMS) and hightemperature (DSC) $C_{p}$ data for all glasses, the fit polynomials used to derive the entropy at $T=298.15 \mathrm{~K}$, and the thermodynamic functions calculated from these polynomials at regularly spaced temperature intervals are available as supporting electronic information (MS Excel spreadsheets) to this publication.

\section{Declarations}

Conflict of interest The authors declare that they have no conflict of interest.

Open Access This article is licensed under a Creative Commons Attribution 4.0 International License, which permits use, sharing, adaptation, distribution and reproduction in any medium or format, as long as you give appropriate credit to the original author(s) and the source, provide a link to the Creative Commons licence, and indicate if changes were made. The images or other third party material in this article are included in the article's Creative Commons licence, unless indicated otherwise in a credit line to the material. If material is not included in the article's Creative Commons licence and your intended use is not permitted by statutory regulation or exceeds the permitted use, you will need to obtain permission directly from the copyright holder. To view a copy of this licence, visit http://creativecommons.org/licenses/by/4.0/.

\section{References}

Adam G, Gibbs JH (1965) On the temperature dependence of cooperative relaxation properties in glass-forming liquids. J Chem Phys 43:139-146

Adjaoud O, Steinle-Neumann G, Jahn S (2008) $\mathrm{Mg}_{2} \mathrm{SiO}_{4}$ liquid under high pressure from molecular dynamics. Chem Geol 256:184-19

Belonoshko AB, Dubrovinsky LS (1996) Molecular and lattice dynamics study of the $\mathrm{MgO}-\mathrm{SiO}_{2}$ system using a transferable interatomic potential. Geochim Cosmochim Acta 60:1645-1656

Benmore CJ, Soignard E, Guthrie M, Amin SA, Weber JKR, McKiernan K, Wilding MC, Yarger JL (2011) High pressure X-ray diffraction measurements on $\mathrm{Mg}_{2} \mathrm{SiO}_{4}$ glass. J Non-Cryst Solids 357:2632-2636

Berman RG, Brown TH (1985) Heat capacity of minerals in the system $\mathrm{Na}_{2} \mathrm{O}-\mathrm{K}_{2} \mathrm{O}-\mathrm{CaO}-\mathrm{MgO}-\mathrm{FeO}-\mathrm{Fe}_{2} \mathrm{O}_{3}-\mathrm{Al}_{2} \mathrm{O}_{3}-\mathrm{SiO}_{2}-\mathrm{TiO}_{2}-\mathrm{H}_{2} \mathrm{O}-$
$\mathrm{CO}_{2}$ : representation, estimation, and high-temperature extrapolation. Contrib Mineral Petrol 89:168-183

Bottinga Y, Richet P (1978) Thermodynamics of liquids silicates, a preliminary report. Earth Planet Sci Lett 40:382-400

Briggs J (1975) Thermodynamics of the glass transition temperature in the system $\mathrm{CaO}-\mathrm{MgO}-\mathrm{Al}_{2} \mathrm{O}_{3}-\mathrm{SiO}_{2}$. Cent Glass Ceram Res Inst Bull 22:73-82

Buchenau U, Prager M, Nücker N, Dianoux AJ, Ahmad N, Phillips WA (1986) Low-frequency modes in vitreous silica. Phys Rev B 34:5665-5673

Courtial P, Richet P (1993) Heat capacity of magnesium aluminosilicate melts. Geochim Cosmochim Acta 57:1267-1275

Dachs E, Bertoldi C (2005) Precision and accuracy of the heat-pulse calorimetric technique: low-temperature heat capacities of milligram-sized synthetic mineral samples. Eur J Mineral 17:251-261

de Koker NP, Stixrude L, Karki BB (2008) Thermodynamics, structure, dynamics, and freezing of $\mathrm{Mg}_{2} \mathrm{SiO}_{4}$ liquid at high pressure. Geochim Cosmochim Acta 72:1427-1441

Gasparik T (1990) A thermodynamic model for the enstatite-diopside join. Am Mineral 75:1080-1091

Ghiorso MS, Carmichael ISE (1980) A regular solution model for met-aluminous silicate liquids: applications to geothermometry, immiscibility, and the source regions of basic magmas. Contrib Mineral Petrol 71:323-342

Ghiorso MS, Carmichael ISE (1987) Modeling magmatic systems: petrologic applications. Rev Mineral 17:467-499

Gillet P, Richet P, Guyot F, Fiquet G (1991) High-temperature thermodynamic properties of forsterite. J Geophys Res 96(B7):11805-11816

Jacobs MHG, de Jong BHWS (2007) Placing constraints on phase equilibria and thermophysical properties in the system $\mathrm{MgO}$ $\mathrm{SiO}_{2}$ by a thermodynamically consistent vibrational method. Geochim Cosmochim Acta 71:3630-3655

Jacobs MHG, Schmid-Fetzer R, van den Berg AP (2017) Phase diagrams, thermodynamic properties and sound velocities derived from a multiple Einstein method using vibrational densities of states: an application to $\mathrm{MgO}-\mathrm{SiO}_{2}$. Phys Chem Miner $44: 43-62$

Kalampounias A, Nasikas N, Papatheodorou G (2009) Glass formation and structure in the $\mathrm{MgSiO}_{3}-\mathrm{Mg}_{2} \mathrm{SiO}_{4}$ pseudobinary system: from degraded networks to ioniclike glasses. J Chem Phys 131:114513. https://doi.org/10.1063/1.3225431

Kojitani H, Akaogi M (1997) Melting enthalpies of mantle peridotite: calorimetric determinations in the system $\mathrm{CaO}-\mathrm{MgO}-\mathrm{Al}_{2} \mathrm{O}_{3}-$ $\mathrm{SiO}_{2}$ and application to magma generation. Earth Planet Sci Lett 153:209-222

Kroeker S, Stebbins JF (2000) Magnesium coordination environments in glasses and minerals: new insight from high-field magnesium-25 MAS NMR. Am Mineral 85:1459-1464

Krupka KM, Hemingway BS, Robie RA, Kerrick DM (1985a) Hightemperature heat capacities and derived thermodynamic properties of anthophyllite, diopside, dolomite, enstatite, bronzite, talc, tremolite and wollastonite. Am Mineral 70:261-271

Krupka KM, Robie RA, Hemingway BS, Kerrick DM, Ito J (1985b) Low-temperature heat capacities and derived thermodynamic properties of anthophyllite, diopside, enstatite, bronzite and wollastonite. Am Mineral 70:249-260

Lacks DJ, Rear DB, Van Orman JA (2007) Molecular dynamics investigation of viscosity, chemical diffusivities and partial molar volumes of liquids along the $\mathrm{MgO}-\mathrm{SiO}_{2}$ join as functions of pressure. Geochim Cosmochim Acta 71:1312-1323

Lange RA, Navrotsky A (1992) Heat capacities of $\mathrm{Fe}_{2} \mathrm{O}_{3}$-bearing silicate liquids. Contrib Mineral Petr 110:311-320

Lange RA, Navrotsky A (1993) Heat capacities of $\mathrm{TiO}_{2}$-bearing silicate liquids: evidence for anomalous changes in configurational 
entropy with temperature. Geochim Cosmochim Acta 57:3001-3011

Lashley JC, Hundley MF, Migliori A, Sarrao JL, Pagliuso PG, Darling TW, Jaime M, Cooley JC, Hults WL, Morales L, Thoma DJ, Smith JL, Boerio-Goates J, Woodfield BF, Stewart GR, Fisher RA, Phillips NE (2003) Critical examination of heat capacity measurement made on a Quantum Design physical property measurement system. Cryogenics 43:369-378

Liebske C, Schmickler B, Terasaki H, Poe BT, Suzuki A, Funakoshi K, Ando R, Rubie DC (2005) Viscosity of peridotite liquid up to $13 \mathrm{GPa}$ : implications for magma ocean viscosities. Earth Planet Sci Lett 240:589-604

Mysen B, Richet P (2005) Silicate glasses and melts: properties and structure. Elsevier, Amsterdam

Nasikas NK, Navrotsky A (2014) Energetics of silica-poor glasses in the systems $\mathrm{MgO}-\mathrm{SiO}_{2}$ and $\mathrm{Mg}_{0.5} \mathrm{Ca}_{0.5} \mathrm{O}-\mathrm{SiO}_{2}$. J Am Ceram Soc 97:451-456

Navrotsky A, Ziegler D, Ostrich R, Maniar P (1989) Calorimetry of silicate melts at $1773 \mathrm{~K}$ : measurement of enthalpies of fusion and of mixing in the systems diopside-anorthite-albite and anorthiteforsterite. Contrib Mineral Petrol 101:122-130

Navrotsky A, Maniar P, Oestrike R (1990) Energetics of glasses in the system diopside-anorthite-forsterite. Contrib Mineral Petrol 105:81-86

Pohl RO (1981) Low temperature specific heats of glasses. In: Phillips WA (ed) Amorphous solids. Topics in current physics, vol 24. Springer, Berlin. https://doi.org/10.1007/978-3-642-81534-8_3

Richet P (1984) Viscosity and configurational entropy of silicate melts. Geochim Cosmochim Acta 48:471-483

Richet NF (2009) Heat capacity and low-frequency vibrational density of states. Inferences for the boson peak of silica and alkali silicate glasses. Physica B 404:3799-3806

Richet P, Bottinga Y (1986) Thermochemical properties of silicate glasses and liquids: a review. Rev Geophys 24:1-25

Richet P, Fiquet G (1991) High-temperature heat capacity and premelting of minerals in the system $\mathrm{CaO}-\mathrm{MgO}-\mathrm{Al}_{2} \mathrm{O}_{3}-\mathrm{SiO}_{2}$. J Geophys Res 96:445-456

Richet P, Robie RA, Hemingway BS (1991) Thermodynamic properties of wollastonite, pseudowollastonite and $\mathrm{CaSiO}_{3}$ glass and liquid. Eur J Mineral 3:475-484

Richet P, Leclerc F, Benoist L (1993) Melting of forsterite and spinel, with implications for the glass transition of $\mathrm{Mg}_{2} \mathrm{SiO}_{4}$ liquid. Geophys Res Lett 20:1675-1678

Richet P, Nidaira A, Neuville DR, Atake T (2009) Influence of cation size on the low-temperature heat capacity of alkaline earth metasilicate glasses. Am Mineral 94:1591-1595

Robie RA, Hemingway BS (1995) Thermodynamic properties of minerals and related substances at $298.15 \mathrm{~K}$ and 1 bar $\left(10^{5}\right.$ Pascals) pressure and at higher temperatures. US Geol Survey Bull 2131:461

Robie RA, Hemingway BS, Wilson WH (1978) Low-temperature heat capacities and entropies of feldspar glasses and of anorthite. Am Mineral 63:109-123

Robie RA, Hemingway BS, Takei H (1982) Heat capacities and entropies of $\mathrm{Mg}_{2} \mathrm{SiO}_{4}, \mathrm{Mn}_{2} \mathrm{SiO}_{4}$, and $\mathrm{Co}_{2} \mathrm{SiO}_{4}$ between 5 and $380 \mathrm{~K}$. Am Mineral 67:470-482

Salje E, Werneke C (1982) The phase equilibrium between sillimanite and andalusite as determined from lattice vibrations. Contrib Mineral Petrol 79:56-67
Sheffield GS (1994) Quantitative measurement of crystalline silica by thermal analysis. Anal Chim Acta 286:125-128

Shiraishi YK, Ikeda K, Tamura A, Saito T (1978) On the viscosity and density of the molten $\mathrm{FeO}-\mathrm{SiO}_{2}$ system. Trans Jpn Inst Met 19:264-274

Speziale S, Reichmann HJ, Marquardt H, Shim S-H (2009) Elasticity of $\mathrm{MgSiO}_{3}$ glass to pressures of the transition zone. (Geophysical Research Abstracts, Vol. 11, EGU2009-12325). General Assembly European Geosciences Union, Vienna

Spice H, Sanloup C, Cochain B, de Grouchy C, Kono Y (2015) Viscosity of liquid fayalite up to $9 \mathrm{GPa}$. Geochim Cosmochim Acta 148:219-227

Spiekermann G, Steele-MacInnis M, Kowalski PM, Schmidt C, Jahn $\mathrm{S}$ (2013) Vibrational properties of silica species in $\mathrm{MgO}-\mathrm{SiO}_{2}$ glasses obtained from ab initio molecular dynamics. Chem Geol 346:22-33

Stebbins JF, Carmichael ISE, Moret LK (1984) Heat capacities and entropies of silicate liquids and glasses. Contrib Mineral Petrol 86:131-148

Tangeman JA, Lange RA (1998) The effect of $\mathrm{Al}^{3+}, \mathrm{Fe}^{3+}$, and $\mathrm{Ti}^{4+}$ on the configurational heat capacities of sodium silicate liquids. Phys Chem Miner 26:83-99

Tangeman JA, Phillips BL, Navrotsky A, Weber JKR, Hixson AD, Key TS (2001) Vitreous forsterite $\left(\mathrm{Mg}_{2} \mathrm{SiO}_{4}\right)$ : synthesis, structure, and thermochemistry. Geophys Res Lett 28:2517-2520

Thiéblot L, Téqui C, Richet P (1999) High-temperature heat capacity of grossular $\left(\mathrm{Ca}_{3} \mathrm{Al}_{2} \mathrm{Si}_{3} \mathrm{O}_{12}\right)$, enstatite $\left(\mathrm{MgSiO}_{3}\right)$, and titanite $\left(\mathrm{CaTiSiO}_{5}\right)$. Am Mineral 84:848-855

Urbain G, Bottinga Y, Richet P (1982) Viscosity of liquid silica, silicates and alumino-silicates. Geochim Cosmochim Acta 46:1061-1072

Weber JKR, Hampton DS, Merkley DR, Rey CA, Zatarski MM, Nordine PC (1994) Aero-acoustic levitation: a method for containerless liquid-phase processing at high temperatures. Rev Sci Instrum 65:456-465

Wilding MC, Benmore CJ, Tangeman JA, Sampath S (2004a) Coordination changes in magnesium silicate glasses. Europhys Lett 67:212-218

Wilding MC, Benmore CJ, Tangeman JA, Sampath S (2004b) Evidence of different structures in magnesium silicate liquids: coordination changes in forsterite- to enstatite-composition glasses. Chem Geol 213:281-291

Wilding MC, Benmore CJ, Weber JKR (2008) In situ diffraction studies of magnesium silicate liquids. J Mater Sci 43:4707-4713

White WP (1919) Silicate specific heats. Am J Sci 47:1-44

Zotov N (2002) Heat capacity of sodium silicate glasses: comparison of experiments with computer simulations. J Phys Condens Matter 14:11655

Publisher's Note Springer Nature remains neutral with regard to jurisdictional claims in published maps and institutional affiliations. 